\title{
Value of Beef Steak Branding: Hedonic Analysis of Retail Scanner Data
}

\author{
Lee L. Schulz, Ted C. Schroeder, and Katharine L. White
}

\begin{abstract}
Consumers rely on experience and credence attributes when purchasing beef from retailers. It is essential for all beef industry sectors to recognize the complexity of consumer buying behavior. A hedonic model is estimated to determine if there are incentives to brand beef steaks, the types of brands that entertain price premiums, and the level of existing premiums. Most branded steaks garnered premiums along with organic claims, religious processing claims, and premium cuts. Factors influencing brand value were new brands targeting emerging consumer trends, brands with regional prominence, and brands positioned as special label, program/breed specific production, and store labels.
\end{abstract}

Key Words: beef steak, brand premium, hedonic modeling

Branding of beef retail products has gained momentum in recent years. In 2004, 42 percent of beef retail products were branded, a figure that grew to 63 percent in 2010 according to the 2010 National Meat Case Study conducted jointly by The Beef Check-off, the National Pork Board, and Cryovac $^{\circledR}$ (National Cattlemen's Beef Association 2010). As the potential value of differentiating and branding retail beef has become apparent, a proliferation of branding strategies has emerged. A review of retail data provided by Freshlook Marketing Group (2011) reveals that there are more than one hundred beef brands now present in U.S. retail markets.

Product differentiation and branding are especially prevalent in beef steaks. The steak market is intriguing because numerous physical attributes and marketing characteristics are being used to differentiate the product. However, there is only limited information available on the implicit value of various steak product attributes and brand labels. In this study, we use revealed preference to determine implicit prices for retail steak

Lee L. Schulz is assistant professor in the Department of Economics at Iowa State University, Ames. Ted C. Schroeder is University Distinguished Professor and Katharine L. White is a former graduate student in the Department of Agricultural Economics at Kansas State University, Manhattan.

The authors acknowledge John Lundeen of the National Cattlemen's Beef Association, The Beef Check-off program, and Dave Shepard of Meat Solutions LLC for providing the data. We appreciate the helpful comments provided by David R. Just and an anonymous reviewer. The views expressed are the authors' and do not necessarily reflect those of the supporters of this research. products associated with descriptive package-label characteristics and product brands.

This study employs a two-step analysis. A hedonic model is used to reveal implicit prices for retail steak characteristics that include both physical (e.g., retail steak cut and bone presence) and credence (e.g., brand name, breed claim, organic production claim, religious processing claim) attributes. Understanding factors that affect implicit price is also of importance. For example, a brand can be thought of as a mix of hedonic, instrumental, and price preferences that represent value to the consumer and are reasonably consistent over time (Zeithaml 1988). To that end, we use estimated brand coefficients from the hedonic price model as a dependent variable to identify the factors associated with brand premiums. Knowing how a branding initiative affects value helps to identify branding strategies that successfully target consumers. Consumers benefit from brand strategies because the brand identifies a known set of attributes at a known level of quality and generally known price range relative to similar products (Owen, Wright, and Griffith 2000). As such, product brands reduce consumers' search costs and uncertainty about product performance.

\section{Previous Research}

Previous studies have elicited various attribute values for retail beef products: eating quality (Hahn and Mathews 2007), fat content (Brester 
et al. 1993, Unnevehr and Bard 1993, Shongwe et al. 2007), tenderness (Feldkamp, Schroeder, and Lusk 2005, Feuz et al. 2004, Lusk et al. 2001, Platter et al. 2005), packaging (Menkhaus et al. 1992, Harrison, Harstad, and Rutstrom 2004), labeling (Loureiro and McCluskey 2000, Lusk and Fox 2002, Loureiro and Umberger 2003), organic production (Boland and Schroeder 2002), and multiple attributes and attribute bundles (Alfnes and Rickertsen 2003, Lusk, Roosen, and Fox 2003, Tonsor et al. 2005, Loureiro and Umberger 2007, Parcell and Schroeder 2007, Ward, Lusk, and Dutton 2008, Martinez 2008, Froehlich, Carlberg, and Ward 2009, Hanagriff, Rhoades, and Wilmeth 2009, Abidoye et al. 2011). Several of these studies paid special attention to the issue of retail beef product branding, recognizing its importance for product differentiation and for providing purchase cues to consumers.

Feldkamp, Schroeder, and Lusk (2005) evaluated consumers' preferences for steaks labeled as generic, guaranteed tender, natural, USDA (U.S. Department of Agriculture) Choice, or Certified Angus Beef ${ }^{\mathbb{R}}$. Consumers were willing to pay an economically important premium exceeding $\$ 2.00$ per steak for Certified Angus Beef ${ }^{\circledR}$ relative to generic steak, suggesting name recognition of the Certified Angus Beef ${ }^{\circledR}$ brand.

Parcell and Schroeder (2007) analyzed paneldiary retail purchase prices for beef products to determine how pricing varied by product, geographic location, store type, sale items, composition (fresh, frozen, or cooked), and package size. Supermarket/grocery store branding was compared to Angus beef branding. Angusbranded medium-quality and high-quality steak cuts commanded premiums of $\$ 1.26$ and $\$ 1.22$ per pound, respectively, relative to supermarket/ grocery-store-branded products. In contrast, lowquality Angus steak cuts appeared to be targeted at price-sensitive consumers as those cuts were sold at a lower price and the Angus brand premium dropped to $\$ 0.76$ per pound. ${ }^{1}$

Ward, Lusk, and Dutton (2008) identified the value consumers place on observable characteristics of fresh beef sold at retail. Premiums for branded

\footnotetext{
1 The steak quality categories employed by Parcell and Schroeder (2007) represented aggregated primal cuts: high-quality (rib, ribeye, tenderloin, and filet mignon), medium-quality (T-bone, sirloin, New York strip, top loin, top sirloin, tip, porterhouse, and round), and lowquality (chuck, blade, arm, shoulder, flank, London broil, cube, and other).
}

steaks and roasts ranged from $\$ 0.00$ to $\$ 6.20$ per pound relative to generic or unbranded products. In general, special and other brands were priced higher than generic and unbranded beef.

Martinez (2008) found a wide degree of variation in brand premiums for branded beef steaks - from $-\$ 0.44$ to $\$ 4.15$ per pound relative to unbranded steaks. Products receiving the largest premiums included branded beef allied with specific production requirements, including natural, organic, source verified, grass-fed, and breed.

Froehlich, Carlberg, and Ward (2009) analyzed consumers' willingness to pay for fresh branded beef in an experimental auction framework. Survey participants preferred branded products to generic with hypothetical premiums that ranged from $\$ 1.12$ to $\$ 1.32$ per 12-ounce steak.

Past research has assessed valuation of branding in the national beef retail sector as well as other attributes that affect price. Our study differs from and builds upon information from previous research in several important ways. First, we rely on retail scanner data rather than hypothetical surveys or experiments to determine implicit market values of individual product characteristics. The scanner data provide a complete sample of sales of all steak products in the participating retail outlets over a five-year period. Second, rather than aggregating brands into arbitrary groupings, we estimate each individual brand premium after adjusting for other product characteristics. This allows us to determine the implicit price of the brand itself separate from the value of other product attributes bundled with the particular brand. Third, we estimate factors associated with implicit brand value. As such, we gain insight into the characteristics that contribute to brand equity and, thus, why consumers respond more favorably to certain brands.

\section{Hedonic Model}

An underlying assumption of the hedonic model is that goods can be distinguished by various product characteristics. As a result, marginal or implicit values can be estimated for each characteristic at the observed purchase price, which is linked to the presence of the particular characteristic.

Rosen (1974) hypothesized that the marginal implicit pricing schedule for a characteristic is a series of equilibriums between supply of and 
demand for the characteristic over time or between markets. According to Rosen (1974), some have inappropriately interpreted the equilibrium points that represent marginal implicit values estimated from the standard hedonic pricing equation as the demand function for that characteristic. Rosen argued that the points are simply a sequence of supply and demand equilibriums that shift due to changes in exogenous supply and demand factors. He showed that standard hedonic price modeling overlooked changing marginal implicit values for different levels of characteristics because only consumer behavior had been considered and producer behavior had been ignored. "Estimated hedonic price-characteristics functions typically identify neither supply nor demand. In fact, those observations are described by a joint-envelope function and cannot by themselves identify the structure of consumer preferences and producer technologies that generate them" (Rosen 1974, p. 54). Accordingly, implicit values for specific product attributes are driven by a combination of consumer demand and product supply.

Following Rosen (1974), we suppose that a market good is composed of $n$ characteristics:

$$
z=\left(z_{1}, z_{2}, \ldots, z_{n}\right)
$$

Prices can be related to the characteristics as

$$
p(z)=p\left(z_{1}, z_{2}, \ldots, z_{n}\right)
$$

where we assume that each product has a market price, $p$, and that the summation of product attributes can be expressed by $z$.

A vector of implicit marginal values is obtained by differentiating $p(z)$ with respect to its $i$ th argument, $z_{i}$ :

$$
p_{i}(z)=\partial p(z) / \partial z_{i}
$$

where $p_{i}$ represents the characteristics' marginal values.

We apply a two-step model. We first estimate implicit values for retail beef steak characteristics in the hedonic model and then estimate factors that affect a brand's estimated value. Estimated brand coefficients from the standard hedonic price model are used as a dependent variable.

\section{Hedonic Model Using Retail Price and Product Characteristics}

We apply a hedonic pricing model to a panel of retail steak sales to estimate the impact of various physical attributes, product claims, and brand names on retail steak pricing. A fixedeffects estimator is hypothesized to control for the time-invariant, unobserved brand factors that may impact retail steak prices. ${ }^{2}$ Consider the model

$$
\begin{gathered}
P_{i j t}=\left(\alpha+c_{j}\right)+x_{i j t} \beta+u_{i j t}, \\
\quad i=1, \ldots, I, j=1, \ldots, J, \text { and } \\
t=1, \ldots, T
\end{gathered}
$$

where $P_{i j t}$ denotes the price of the $i$ th steak package with the $j$ th brand for the $t$ th time period, $\alpha$ is the overall model intercept, $c_{j}$ is the time-invariant, individual brand effect considered to be part of the intercept, $x_{i j t}$ is a $1 \times \mathbf{K}$ row vector of observable variables associated with product characteristics, $\beta$ is a $\mathbf{K} \times 1$ parameter vector of marginal effects of product attributes, and $u_{i j t}$ represents the idiosyncratic errors that change across $i, j$, and $t$ (Wooldridge 2002, Baltagi 2008). The $c_{j}$ component consists of a dummy variable for each individual brand. The regression is a least squares dummy variable (LSDV) model-a fixed-effects model for which the slopes are constant but the intercepts differ according to the cross-sectional unit, which in this case is the brand.

The data set analyzed in this study includes repeated observations per cross-section and over time. As a result, errors are potentially serially correlated (i.e., correlation over $t$ for a given $i$ and $j$ ) and/or heteroskedastic. Inclusion of fixed individual-specific effects can reduce serial correlation in the errors (Cameron and Trivedi

2 The Durbin-Wu-Hausman test (Wu 1973) was used to determine if the time-invariant, unobservable factors should be treated as a fixed effect or as a random effect. We obtained group means for the timeinvariant variables and added them to the estimated random-effects model. We then tested the joint hypothesis that the coefficients on the group means are all zero. The hypothesis that the individual effects are uncorrelated with the other regressors was rejected. This suggests that the effects are correlated with other variables in the model so the fixedeffects model is appropriate. 
Table 1. Description of Variables and Summary Statistics of Sale Observations

\begin{tabular}{|c|c|c|c|}
\hline Variable & Description & Mean & Standard Deviation \\
\hline \multicolumn{4}{|c|}{ Dependent Variable } \\
\hline Price $_{i j t}$ & Retail price for package $i$ of brand $j$ during week $t$ (dollars per pound) & 7.85 & 4.27 \\
\hline \multicolumn{4}{|c|}{ Independent Variables } \\
\hline Brand $_{j}$ & Binary variables for brand $j^{\text {a }}$ & NA & NA \\
\hline Breed $_{i t}$ & Binary variable $=1$ if a breed claim is present, 0 otherwise & 0.48 & 0.50 \\
\hline Organic $_{i t}$ & Binary variable $=1$ if an organic claim is present, 0 otherwise & 0.04 & 0.19 \\
\hline Religious $_{i t}$ & Binary variable $=1$ if a religious processing claim is present, 0 otherwise & 0.06 & 0.24 \\
\hline Bone $_{i t}$ & Binary variable $=1$ if bone is present, 0 otherwise & 0.20 & 0.40 \\
\hline$C u t_{i c t}$ & Binary variables for retail cut $(c)$ for package $i$ & (Figure 1) & \\
\hline Week $_{i t}$ & $\begin{array}{l}\text { Binary variable for week of package sale } i \\
(1 / 11 / 2004=1, \ldots, 3 / 29 / 2009=273)\end{array}$ & NA & NA \\
\hline
\end{tabular}

Notes: ${ }^{a}$ Proportion of sales associated with each brand are not presented due to confidentiality restrictions.

2005). ${ }^{3}$ A Breusch-Pagan/Cook-Weisberg test rejects the null hypothesis that the error variances are constant. White's heteroskedasticity-consistent covariance matrix is used to estimate standard errors. ${ }^{4}$

Following Greene (2003), we use an F-test that resembles the structure of the F-test for R-square changes to test the hypothesis that the brandspecific constants are all equal, thereby testing the significance of the individual brand's fixed effects. The F-ratio used for this test is

$$
\begin{gathered}
\mathrm{F}\left(n-1, \sum_{i=1}^{n} T_{i}-n-K\right) \\
=\frac{\left(R_{L S D V}^{2}-R_{\text {Pooled }}^{2}\right) /(n-1)}{\left(1-R_{L S D V}^{2}\right) /\left(\sum_{i=1}^{n} T_{i}-n-K\right)}
\end{gathered}
$$

where LSDV and Pooled indicate LSDV and pooled models with only a single intercept for $n$ brands and $T$ time periods. Under the null

\footnotetext{
3 To test for serial correlation, we must specify a time variable. However, for this data there was no consistent time variable because we have more than one observation per time period per cross-section. Thus, to detect the presence of first-order serial correlation, we computed the mean of the errors from equation (4) for each unique date. These mean errors were used in a Cochrane-Orcutt procedure, which showed a $\rho$ first-order autocorrelation estimate that was not statistically significant.

${ }^{4}$ White's robust standard-error estimation was used instead of feasible generalized least squares (FGLS) because the loss of efficiency in parameter estimates is rather small given the large sample size. Results using the FGLS estimator were quantitatively similar.
}

hypothesis that the brand-specific constants are the same, this statistic is an F-random variable in which there are $n-1$ degrees of freedom for the numerator and $n T-n-K$ degrees of freedom for the denominator. The value of the F-random variable is $\mathrm{F}(61,198,349)=1,108.35(p$-value $=0.000)$. This shows that the brand-specific constants differ and that a pooled model with one intercept is not appropriate. Overall, we conclude that the alternative pooled model omits important timeinvariant brand effects so we use a fixed-effects model.

The retail steak price is modeled as

$$
\begin{aligned}
\text { Price }_{i j t}= & \alpha+\sum_{j=1}^{62} \beta_{1 j} \text { Brand }_{j}+\beta_{2} \text { Breed }_{i t}+\beta_{3} \text { Organic }_{i t} \\
& +\beta_{4} \text { Religious }_{i t}+\beta_{5} \text { Bone }_{i t}+\sum_{c=1}^{33} \beta_{6 c} \text { Cut }_{i c t} \\
& +\sum_{t=1}^{273} \beta_{7 t} \text { Week }_{i t}+u_{i j t}
\end{aligned}
$$

where $i$ refers to steak package (package here refers to weekly sales of the specific product), $j$ refers to brand, and $t$ refers to time period. Definitions for the rest of the variables are shown in Table 1.

\section{Brand Value Model}

Brand value is the value beyond the physical and credence characteristics associated with the 
product's production or processing. There are numerous steak brands in the market aimed at appealing to different consumer preferences. It is therefore difficult to identify the characteristics that drive an individual brand's premium using hedonic model parameter estimates on binary brand variables. For example, brands may differ across multiple dimensions, including the brand name's longevity and the breadth of its distribution. The implicit values needed to determine brand value differences are obtained from estimating equation (6). Those implicit values $\left(\beta_{1 j}\right.$ estimates from equation (6) are used to determine the factors that contribute to a brand's value. The brand value determination model takes the form

$$
\begin{aligned}
\text { (7) } \text { BrandValue }_{j}= & \alpha+\sum_{a=1}^{4} \beta_{1 a} \text { BrandAge }_{a j}+\sum_{l=1}^{3} \beta_{2 l} \text { Location }_{l j} \\
& +\sum_{p=1}^{4} \beta_{3 p} \text { Positioning }_{p j}+\beta_{4} \text { ChoicePlus }_{j} \\
& +\beta_{5} \text { MultiMeat }_{j}+\varepsilon_{j}
\end{aligned}
$$

where $j$ refers to brand. Definitions for the rest of the variables are shown in Table 2.

Table 2. Description of Variables and Summary Statistics of Brands

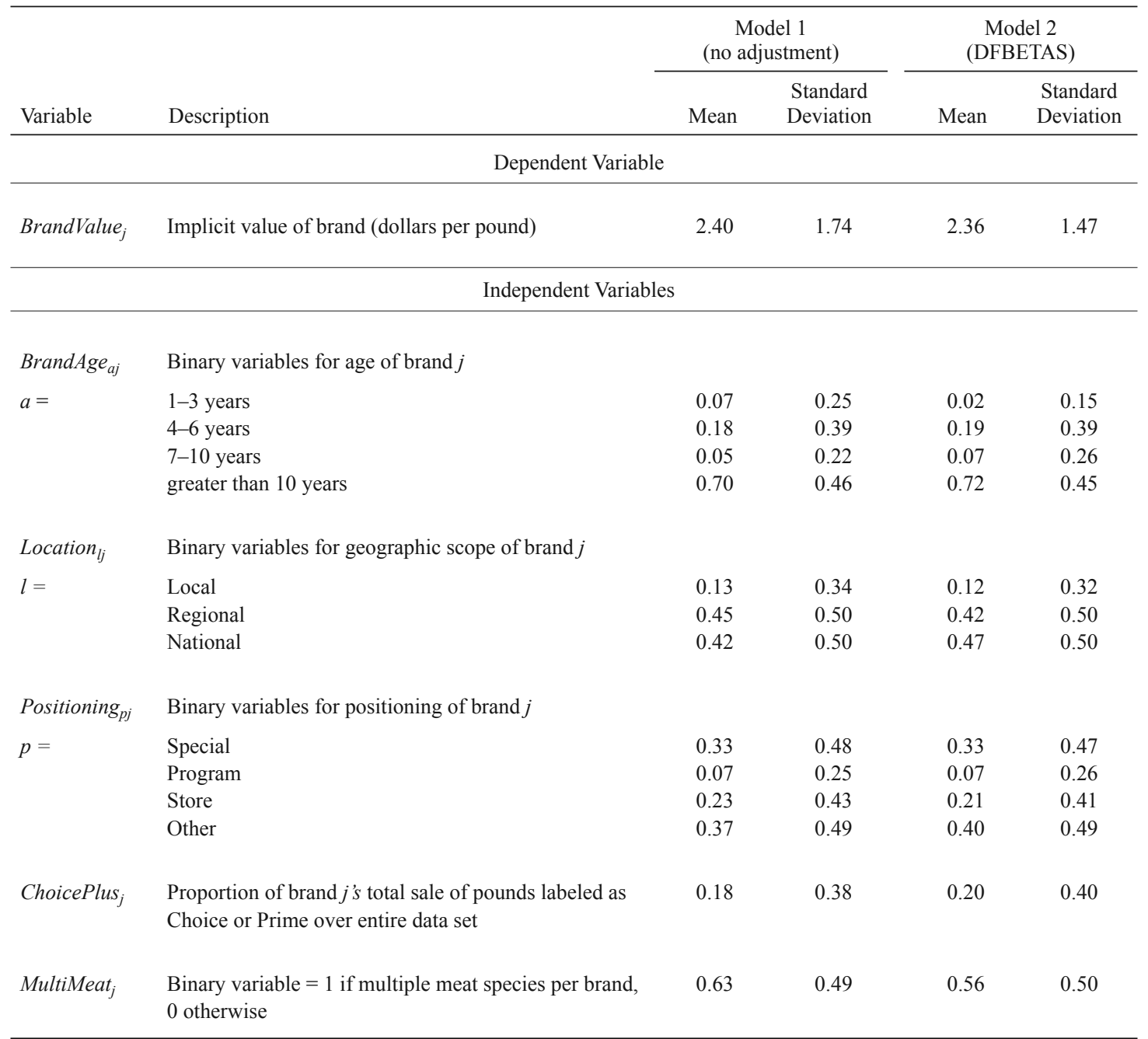

Note: Observations that were deemed to be influential and removed from model 2 data were $\mid$ DFBETAS $\mid>2 \sqrt{n}$ where $n$ is the number of observations used (Belsley, Kuh, and Welsch 1980). 
Using coefficient estimates as dependent variables in subsequent regression analyses is common (e.g., Bowman and Ethridge 1992, Chiou, Chen, and Capps 1993, Jusko and Shively 2005). Achen (2005) reviewed several alternative estimation techniques for two-step regression modeling. He concluded that the method we employ of estimating each equation separately by ordinary least squares is acceptable and even preferable under certain conditions to other potential methods. Achen (2005) noted that the second-stage model estimated using ordinary least squares for each equation can be delicate if the firststage is not well specified. Specification errors in the first-stage will cause biases and inconsistencies in the second-stage even if the second-stage has no problem of its own. He further suggested that the first-stage sample size should be orders of magnitude larger than the second-stage sample and that there should be no large influential points in the second-stage parameters. Our models and associated estimates pass all of these conditions as discussed in the results.

\section{Data}

Scanner data representing steak purchases in U.S. retail outlets from January 1, 2004, through March 31, 2009, were obtained from Freshlook Marketing Group, which collects InfoScan data on meat department random-weight sales from retail food stores nationwide. The data set contains 198,719 weekly aggregated sales observations as value of pounds sold by brand name, retail cut, quality grade, breed claim, organic production claim, religious processing claim, and presence of bone.

Due to confidentiality restrictions, we cannot identify the specific brand names. We therefore label the brands numerically as Brand 1 through Brand 62. Likewise, we simply note whether a specific breed claim was present or not. Brands carrying an organic claim must be certified by an accredited certifying agent, which verifies that the meat was produced and handled according to guidelines set forth in the Organic Foods Production Act (OFPA) of 1990 (Title 21, P.L. 101-624). Synthetic chemicals are not allowed and the producer and handlers must follow a plan agreed to by the certifying agent (USDA 2010). Religious processing claims consist of Kosher, Kosher-Glatt, Halal, and no religious claim. We combined all religious claims into a single binary variable equal to one if the product had a religious processing claim and zero otherwise.

Previous studies (e.g., Parcell and Schroeder 2007, Ward, Lusk, and Dutton 2008) included USDA quality grades of Prime, Choice, and Select and ungraded meat to categorize meat quality. There is considerable collinearity present in our data set between individual brands and quality grades. Consequently, we estimate a model that excludes quality grade variables since they are embedded in the brand effects.

Thirty-three steak cuts (Figure 1) are represented in the data. Cuts that are considered Premium are expected to have positive coefficients for the cutspecific binary variables included in the hedonic model while Everyday steak cuts are expected to have negative coefficient estimates (the Premium and Everyday categories come from The Beef Check-off Program (2008)). In addition, cuts that retain a bone $($ Bone $=1)$ are expected to have a lower retail price per pound than boneless cuts. To adjust for changing aggregate steak prices over time, we include weekly binary variables.

In addition to details of aggregate weekly sales, the data set contains information about how the characteristics of each individual brand are likely to affect the brand's value. The variables defined in Table 2 are used in step two of the analysis to regress the estimated brand premiums from the hedonic model against factors associated with each brand name. Brand longevity is the continued presence of a brand in the relevant market (Banbury and Mitchell 1995, Li 1995). The longevity of a brand is essential for a firm's survival because it is linked to performance measures such as profitability and market share (Kanter and Brinkerhoff 1981, Suarez and Utterback 1995). We categorized brand longevity into five segments: (i) three years and less (7 percent), (ii) four to six years (18 percent), (iii) seven to ten years (5 percent), and (iv) eleven years and greater (70 percent). Brands having a longer presence in the market are expected to have greater consumer recognition and thus higher brand value.

The data set consists of 60 steak brands. ${ }^{5} \mathrm{We}$ classify brands into the following geographic distribution categories. A local brand is distributed only within a local geographic area and is privately

\footnotetext{
${ }^{5}$ Unbranded products and products that are included in a conglomerate "store" grouping are not included in the data set for stage two of the analysis. Thus, the number of brands is reduced from 62 to 60 .
} 


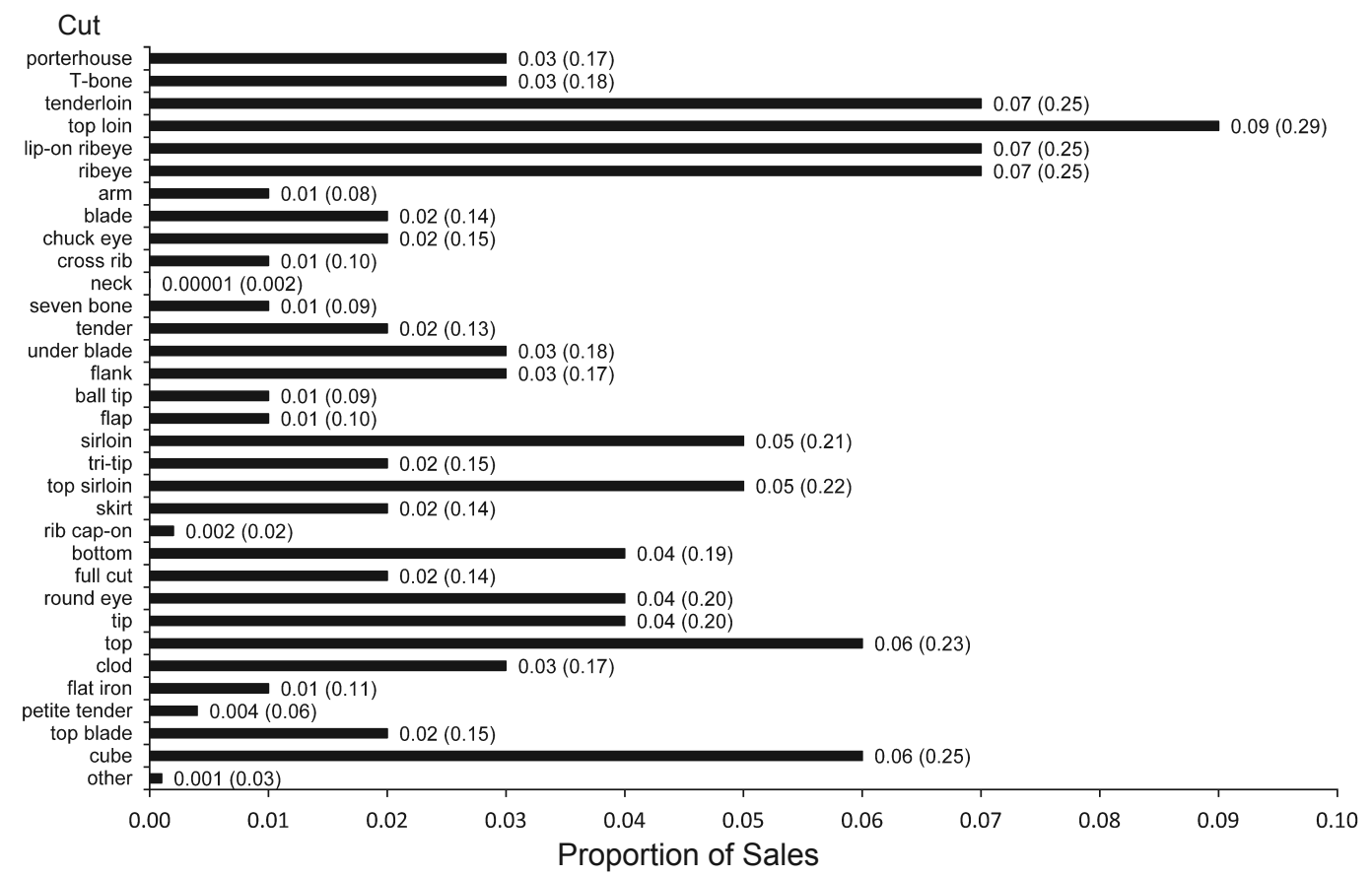

\section{Figure 1. Retail Steak Cut Proportion of Sales}

Notes: Following The Beef Check-off (2008), we classify retail steak cuts as Premium (porterhouse, T-bone, tenderloin, top loin, lip-on ribeye, and ribeye) and Everyday (arm, blade, chuck eye, cross rib, neck, seven bone, tender, under blade, flank, ball tip, flap, sirloin, tri-tip, top sirloin, skirt, rib cap-on, bottom, full cut, round eye, tip, top, clod, flat iron, petite tender, top blade, cube, and other). Standard deviations are shown in parentheses.

owned and controlled by a small company. A regional brand is distributed regionally to retail outlets and is owned and controlled by a private company. Distribution is to one or more regions but is not nationwide. A national brand is distributed to retail locations nationwide and is controlled by the company or the supplier(s) that owns the brand. Of the 60 brands in this analysis, 8 were local, 27 were regional, and 25 were national.

A brand's geographic prominence can have a positive or a negative relationship with its value. Previous research supports this assertion of mixed expectations regarding the geographic scope of a brand and the effect of that distribution on its value. Jekanowski et al. (2000) surveyed consumers in Indiana and concluded that they were willing to pay a premium for locally produced meat. This is consistent with similar results obtained from California (McGarry-Wolf and Thulin 2000), Colorado (Thilmany, Grannis, and Sparling 2003), and Chicago and Denver (Umberger et al. 2003). A national brand has a much larger overall volume and benefits from greater advertising expenditures, and, as such, it garners broader general consumer awareness that can secure greater brand value and a higher price (Parcell and Schroeder 2007). Previous studies (Darby et al. 2006, Hu 2007) have shown that taste is the single most important attribute in repeat purchases of a food, and consumers are more likely to have had experience with a nationally branded product than with a locally or regionally distributed one. In the early days of branded beef in the United States, some of the major beef brands were spearheaded by producer groups (e.g., the American Angus Association developed Certified Angus Beef ${ }^{\mathbb{R}}$ ). The early emergence of nationally branded beef products in the United States encouraged retailers and packers to establish brands.

Because individual branded products are positioned to appeal to specific groups of consumers, we include brand positioning in our analysis to determine how types of brands differ in value. Brand types used in the study include special (33 percent), program (7 percent), store (23 percent), and other (37 percent). These 
categories are consistent with those of Ward, Lusk, and Dutton (2008). Special brands carry labels that relate information about practices used in production, such as "natural" or "organic," that involve higher production costs (Yanik et al. 1999). Meats labeled as special are expected to have a high brand value. Program brands are breedspecific products (e.g., Angus beef). Generally, we expect that a breed name on the package helps to promote consumer confidence and loyalty due to the accountability and product assurance that come with the breed name. Store brands are specific to certain retail stores or chains of stores. Other brands are meat brands that could not be classified readily into one of the other three types; they were most often owned by a processor or meat market.

Quality grade variables are excluded from the retail price estimation because they are embedded with the brand effects. Because Prime and Choice quality grades signal high quality, we expect those labels to increase a brand's value. We thus included the proportion of pounds sold by a particular brand that was labeled as Choice or Prime (ChoicePlus) in the brand-value-determination model.

Brand recognition can be strengthened by branding multiple food products. For example, a number of brands offer beef, poultry, and/or pork products. Multiproduct brands may enjoy greater brand equity because of broader consumer recognition of and loyalty to the brand name across food products. Sixty-three percent of the brands in our sample represent products from companies offering multiple meat brands.

\section{Implicit Prices of Retail Beef Steak Characteristics}

In empirical estimation, the theoretical foundation for hedonic models provides little guidance on appropriate functional form. Here, steak is assumed to be separable and additive in the various characteristics (e.g., breed claim, organic production claim, religious processing claim, cut), suggesting a linear relationship. ${ }^{6}$ This implies that individual steak characteristics can be bundled, packaged, and purchased in any combination.

\footnotetext{
${ }^{6}$ We also considered a log-linear model. Box-Cox regressions suggest that a log-linear functional form is more appropriate. However, the difference in "fit" is slight. In this case, the linear functional form is preferred because the price-per-pound interpretation is more straightforward for step-one and step-two modeling. General conclusions from each model specification are qualitatively the same.
}

Table 3. Determinants of Steak Price per Pound, January 1, 2004, through March 31, 2009

\begin{tabular}{|c|c|}
\hline Variable & $\begin{array}{l}\text { Coefficient } \\
\text { Estimate }\end{array}$ \\
\hline Intercept & $\begin{array}{l}6.39 * * * \\
(0.08)\end{array}$ \\
\hline $\operatorname{Brand}_{j}$ (default: unbranded) & (Figure 2) \\
\hline Breed & $\begin{array}{l}-1.27 * * * \\
(0.03)\end{array}$ \\
\hline Organic & $\begin{array}{l}2.98^{* * *} \\
(0.05)\end{array}$ \\
\hline Religious & $\begin{array}{l}1.18^{* * *} \\
(0.04)\end{array}$ \\
\hline Bone & $\begin{array}{l}-0.77 * * * \\
(0.02)\end{array}$ \\
\hline$C u t_{c}$ (default: sirloin) & (Figure 3) \\
\hline $\begin{array}{lr}\text { Observations } & 198,179 \\
\text { R-square } & 0.73\end{array}$ & \\
\hline $\begin{array}{l}\text { Notes: Coefficient estimates refer } t \\
\text { dollars per pound from a one-unit } \\
\text { ceteris paribus. Three }(* * *) \text { aster } \\
\text { different from zero at the } 0.01 \\
\text { parentheses under the coefficient es }\end{array}$ & $\begin{array}{l}\text { ail steak price } \\
\text { endent variabl } \\
\text { nts significant } \\
\text { s are shown }\end{array}$ \\
\hline
\end{tabular}

Empirical results for our hedonic pricing model are presented in Table $3 .^{7}$ The coefficient estimates refer to changes in retail steak prices in dollars per pound from one-unit changes in the independent variables, ceteris paribus. A positive coefficient represents a premium for the particular steak characteristic while a negative coefficient indicates a discount.

Brand coefficients (Figure 2) range from $-\$ 1.24$ to $\$ 5.77$ per pound relative to unbranded steak products. Ward, Lusk, and Dutton (2008) found premiums of $\$ 0.00$ to $\$ 6.20$ per pound relative to generic and unbranded roasts and steaks. While their range is similar to ours, notable differences exist in measurements between the studies. Our study estimates individual brand coefficients

\footnotetext{
7 Influence diagnostics (Belsley, Kuh, and Welsch 1980) determined that the coefficient estimates are not significantly influenced by a specific subset of outlier data.
} 


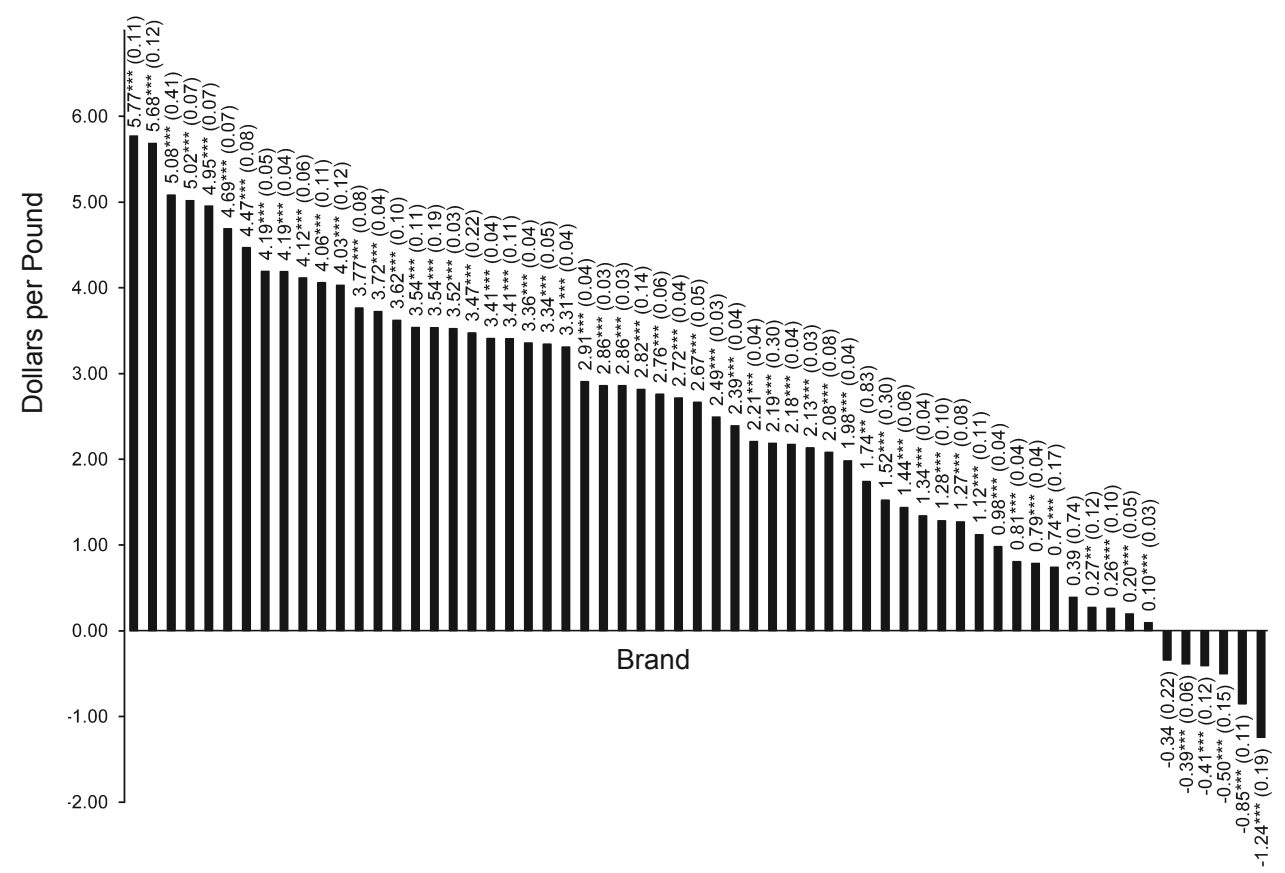

Figure 2. Estimated Steak Brand Premium Compared to Unbranded Product, January 1, 2004, through March 31, 2009

Notes: Coefficient estimates refer to a change in retail steak price in dollars per pound for a particular brand, ceteris paribus. One $(*)$, two $(* *)$, and three $(* * *)$ asterisks denote coefficients significantly different from zero at the $0.10,0.05$, and 0.01 level, respectively. Standard errors are shown in parentheses.

as opposed to brands grouped into categories (special, program/breed, store, other, and none/ generic). Furthermore, we employ nationwide retail scanner data while Ward, Lusk, and Dutton (2008) used data from a sample of retail stores in Oklahoma City and Tulsa, Oklahoma, and in Denver, Colorado. Martinez (2008) found steak brand premiums that ranged from $-\$ 0.44$ to $\$ 4.15$ per pound in analysis of Nielson Homescan panel data.

The breed claim coefficient in this analysis indicates that steaks labeled with a breed claim, ceteris paribus, have a $\$ 1.27$ per pound lower price on average than products without one. We expected breed claim to have a positive coefficient in that it would appeal to consumers who have a breed preference. Furthermore, the breed claim can be omitted from the product label if it reduces value. Perhaps breed claims have proliferated to the point that they do not, by themselves, enhance product value. In further analysis that cannot be reported due to confidentiality restrictions, we determined that some brands with breed claims garner a premium while others are discounted. Thus, to predict the price of a steak that has a breed claim, the brand parameter estimate and breed claim estimate must be considered together.

Organic production of steaks garners a premium of $\$ 2.98$ per pound relative to nonorganic steak products. These results are consistent with expectations; organic products tend to exhibit higher prices because they represent a particular niche market that is costly to supply relative to conventionally produced products. The organic price premium also may indicate growing consumer demand for organically produced products. The intuition for religious processing claims is similar, and those products exhibit a premium of $\$ 1.18$ per pound.

As expected, bone-in retail cuts are discounted relative to boneless products, which have a $\$ 0.77$ premium per pound. Shongwe et al. (2007) found that bone-in T-bone and rump steaks were discounted 23 percent relative to boneless products. 


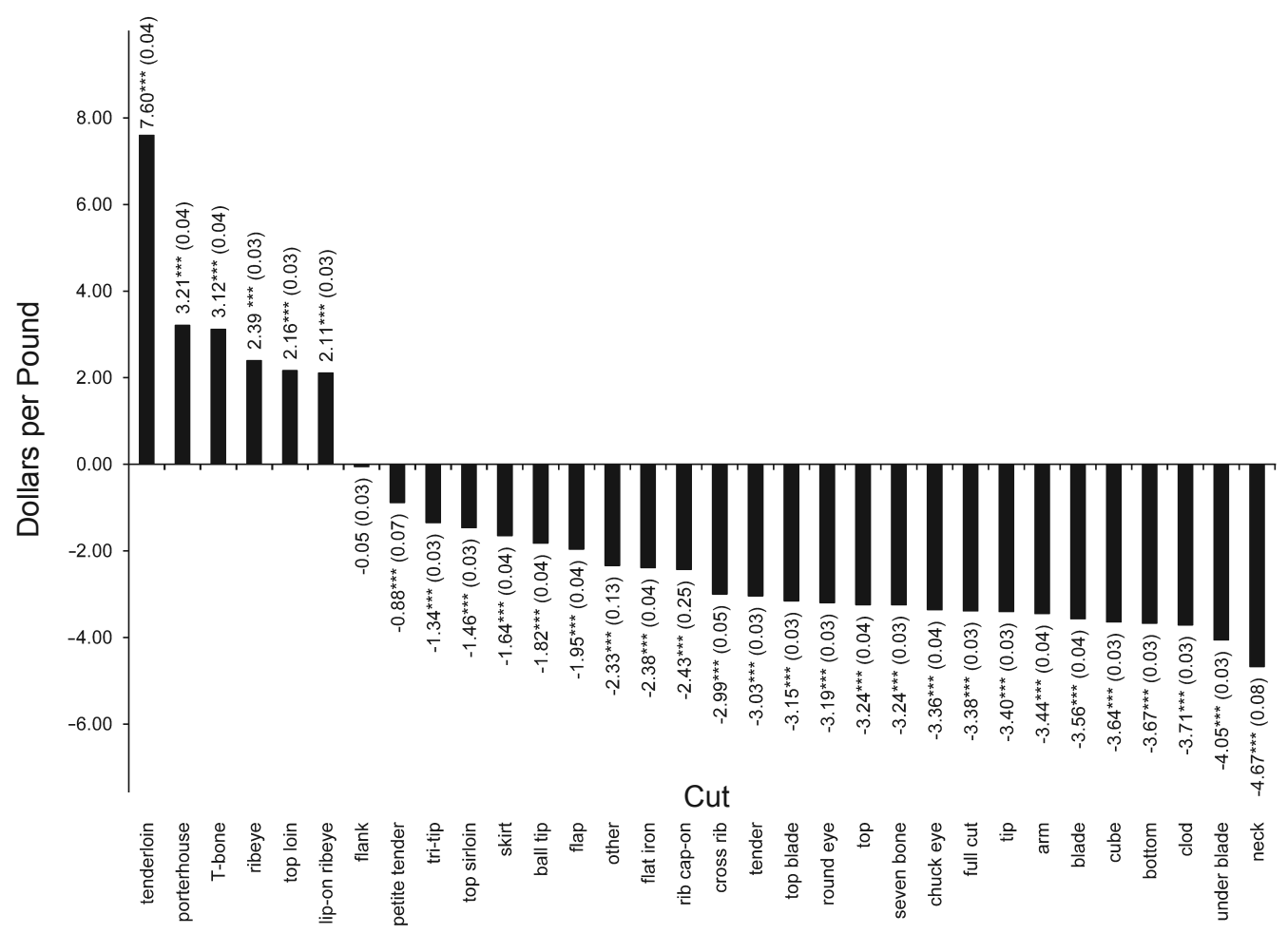

Figure 3. Estimated Retail Premium for Steak Cuts Compared to Sirloin Steak, January 1, 2004, through March 31, 2009

Notes: Following The Beef Check-off (2008), we classify retail steak cuts as Premium (porterhouse, T-bone, tenderloin, top loin, lip-on ribeye, and ribeye) and Everyday (arm, blade, chuck eye, cross rib, neck, seven bone, tender, under blade, flank, ball tip, flap, sirloin, tri-tip, top sirloin, skirt, rib cap-on, bottom, full cut, round eye, tip, top, clod, flat iron, petite tender, top blade, cube, and other). Coefficient estimates refer to a change in retail steak price in dollars per pound for a particular retail cut, ceteris paribus. Three $(* * *)$ asterisks denote coefficients significantly different from zero at the 0.01 level. Standard errors are shown in parentheses.

Unnevehr and Bard (1993) found that the perpound price for bone-in cuts was sharply lower at $\$ 1.11$ for rib steaks, $\$ 0.91$ for loin steaks, and $\$ 0.30$ for sirloin steaks.

The steak-cut coefficients in our model coincide with classifications by The Beef Check-off (2008) for Premium and Everyday steaks. Steaks in the Premium category are tenderloin, porterhouse, T-bone, ribeye, top loin, and lip-on ribeye, and they garner premiums (Figure 3 ) relative to sirloin steaks with an average premium of $\$ 3.43$ per pound. The tenderloin cut receives the highest premium, $\$ 7.60$ per pound. The premium for steaks in the Everyday category is negative, ranging from $-\$ 0.05$ to $-\$ 4.67$ per pound. Everyday steaks are likely discounted because consumers perceive these cuts as being less flavorful and less tender. Additional processing and preparation often are necessary when cooking such steaks.

\section{Retail Value of Beef Steak Brands}

The preceding discussion highlights the value that consumers place on descriptive characteristics of steak and identifies individual brand values. But what factors influence brand value? The second step of the analysis provides insight into this question. According to Achen (2005), two-step estimation is viable when (i) first-stage models are well specified, (ii) first-stage samples (of size $n_{j}$ ) are much larger than second-stage samples (of size $m$ ), and (iii) influential points in the second stage are 
thoroughly assessed. We assert that our first-stage specification is appropriate. Next, there should be more retail steak prices by an order of magnitude than there are brands. Achen (2005) found that simple examples indicate that consistency requires

Table 4. Determinants of Brand Value per Pound

\begin{tabular}{|c|c|c|}
\hline \multirow[b]{2}{*}{ Variable } & \multicolumn{2}{|c|}{ Coefficient Estimates } \\
\hline & $\begin{array}{c}\text { Model 1 } \\
\text { (no adjustment) }\end{array}$ & $\begin{array}{c}\text { Model } 2 \\
\text { (DFBETAS) }\end{array}$ \\
\hline Intercept & $\begin{array}{c}0.41 \\
(0.63)\end{array}$ & $\begin{array}{c}0.09 \\
(0.50)\end{array}$ \\
\hline \multicolumn{3}{|c|}{ 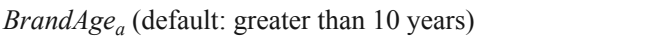 } \\
\hline $1-3$ years & $\begin{array}{l}1.69 * * \\
(0.82)\end{array}$ & $\begin{array}{l}1.94 * \\
(1.00)\end{array}$ \\
\hline $4-6$ years & $\begin{array}{l}-0.71 \\
(0.59)\end{array}$ & $\begin{array}{l}-0.60 \\
(0.46)\end{array}$ \\
\hline $7-10$ years & $\begin{array}{l}-0.28 \\
(1.02)\end{array}$ & $\begin{array}{l}-0.76 \\
(0.71)\end{array}$ \\
\hline \multicolumn{3}{|c|}{ Location $_{l}$ (default: national) } \\
\hline local & $\begin{array}{c}0.09 \\
(0.62)\end{array}$ & $\begin{array}{c}0.85 \\
(0.52)\end{array}$ \\
\hline regional & $\begin{array}{c}0.76^{*} \\
(0.43)\end{array}$ & $\begin{array}{l}1.02 * * * \\
(0.32)\end{array}$ \\
\hline \multicolumn{3}{|c|}{ Positioning $_{p}$ (default: other) } \\
\hline special & $\begin{array}{l}2.32 * * * \\
(0.48)\end{array}$ & $\begin{array}{l}2.54 * * * \\
(0.41)\end{array}$ \\
\hline program & $\begin{array}{l}1.54 * \\
(0.90)\end{array}$ & $\begin{array}{l}2.91 * * * \\
(0.76)\end{array}$ \\
\hline store & $\begin{array}{l}1.31 * * \\
(0.64)\end{array}$ & $\begin{array}{l}2.34 * * * \\
(0.55)\end{array}$ \\
\hline ChoicePlus & $\begin{array}{c}0.73 \\
(0.61)\end{array}$ & $\begin{array}{c}0.32 \\
(0.52)\end{array}$ \\
\hline MultiMeat & $\begin{array}{c}0.56 \\
(0.48)\end{array}$ & $\begin{array}{c}0.51 \\
(0.40)\end{array}$ \\
\hline Observations & 60 & 43 \\
\hline R-square & 0.43 & 0.70 \\
\hline
\end{tabular}

Notes: Coefficient estimates refer to a change in brand value in dollars per pound from a one-unit change in the independent variable, ceteris paribus. One (*), two $(* *)$, and three $(* * *)$ asterisks denote coefficients significantly different from zero at the $0.10,0.05$, and 0.01 level, respectively. Standard errors are in parentheses under the coefficient estimates. Observations that were deemed to be influential and removed from model 2 estimation are $\mid$ DFBETAS $\mid>2 \sqrt{n}$ where $n$ is the number of observations used (Belsley, Kuh, and Welsch 1980). $m / n \rightarrow 0$ asymptotically. We clearly adhere to the sample-size principle as $60 / 198,179=0.0003$. Finally, to determine if the results of the secondstep regression analysis are significantly influenced by outlier observations, we compute influential diagnostics, namely, DFBETAS. According to Belsley, Kuh, and Welsch (1980, p. 263), "DFBETAS point to characteristics of the data to which the coefficient estimates or their estimated standard errors are particularly sensitive and are especially useful for examining the suitability of the data for structural estimation." Our discussion of results follows our base model, which did not eliminate any potential outlier observations (model 1). However, we highlight specific results that may be impacted by outlier data by comparing the base model to model 2. In model 2, we delete any influential outlier observations as determined by the DFBETAS.

The results of estimating equation (7) are presented in Table $4 .{ }^{8}$ New brands - brands that have existed in the industry for three years or lesshave a $\$ 1.69$ per pound premium relative to brands that have been in the industry for greater than ten years. When consumers can choose among many brands, producers tend to emphasize development of new and different product attributes rather than the value found in traditional products (Outlaw, Anderson, and Padberg 1997). Our estimates indicate that new brands are typically introduced at premium prices. Perhaps newly launched brands are targeting specific, emerging consumer trends. How many of these brands will be successful in sustaining a premium value over time is unknown but some likely will fail. The estimates generated for medium-aged brands are not statistically significant.

Regional brands garnered a $\$ 0.76$ premium per pound relative to national brands. The alternative model estimated after deleting influential outliers indicates that the regional premium could be as large as $\$ 1.02$ per pound relative to national brands. This is a surprising result since regional brands have smaller market shares and presumably less general consumer recognition. In contrast,

\footnotetext{
${ }^{8}$ Additional diagnostic tests were conducted for the brand-value model. The presence of heteroskedasticity was tested using the BreuschPagan/Cook-Weisberg test, which failed to reject the null hypothesis of constant variances. Statistics for variance inflation factors indicated no problem with multicollinearity. Box-Cox regressions that compared the goodness-of-fit of models in which the dependent variable was in levels or logs suggest that a linear functional form is more appropriate.
} 
local brands do not differ statistically in terms of brand equity relative to national brands.

Our results support recent changes firms have made to differentiate products through brand positioning. Estimates of positioning in our analysis show that special brands sell for $\$ 2.32$ per pound more than other brands; while program and store brands have premiums of $\$ 1.54$ and $\$ 1.31$ per pound, respectively. The alternative model adjusted for influential observations shows that these premiums could be as large as $\$ 2.54$ for special, \$2.91 for program, and \$2.34 for store brands relative to other brands.

Both models fail to show a statistically significant effect for (i) the proportion of pounds labeled Choice or Prime (ChoicePlus) and (ii) whether the company that owns the brand also has meat from other species carrying the same brand name (MultiMeat).

\section{Conclusions and Implications}

The objective of this study was to determine how product attributes of retail beef steak affect prices. We were particularly interested in determining implicit price premiums for steak brands. Certain brands garner premiums while others receive discounts relative to unbranded products. We found that 55 of the 62 retail steak brands evaluated received positive premiums; the remaining brands were discounted relative to unbranded products. Characteristics other than brand that garner a premium include organic production claims, religious processing claims, and boneless products. Premium steaks, such as tenderloin, porterhouse, T-bone, ribeye, top loin, and lip-on ribeye, exhibit premiums when compared to sirloin steaks. Steak cuts perceived to be of lower quality were discounted. Consumers exhibit complex purchasing behavior that various beef industry sectors are taking into consideration in their efforts to provide desired products. Our results identify implicit prices of numerous product attributes, providing every sector of the beef industry with information regarding how to improve branding strategies.

Newly introduced brands tend to have higher prices than existing products. They are often developed in response to consumer trends regarding quality and safety and involve additional production costs. Products that successfully align with emerging consumer preferences may be able to capture premium prices. We lacked data necessary to determine failure rates for newly developed products, a factor that must be kept in mind when determining pricing strategies.

Branding often targets consumers who prefer specific product characteristics, such as certified breed and natural and organic production claims. Also, branding tied to a particular retailer or store can help to promote and ensure confidence and loyalty. Tonsor, Schroeder, and Pennings (2009) concluded that store reputation influences consumer perceptions about products' quality and safety and that store branding is an additional way to leverage value from a store's reputation. We expect store brands to play a substantial and growing role in branded beef products in the future.

Brand value is not strongly associated with the quality grade of the meat. Most branded beef products do not use quality grade as a substantial part of the product labeling scheme even though the grade is often part of the brand's specifications. Consumers may not understand or may be poorly informed about formal beef grades (Cox, McMullen, and Garrod 1990).

For a branded steak product to be successful, there must be a strong link between consumers' attitudes and the attributes offered by the brand. Marketers must realize that consumer perceptions change over time as a result of new information, increased competition in a product category, and changing expectations. The dynamic nature of the retail beef market suggests that marketers must track perceptions over time and continually align their product and branding strategies with changing views.

An important limitation of this analysis is that we could not determine whether implicit premiums for product attributes are driven more by consumer demand or by supply. That is, a product attribute such as an organic production claim has a statistically significant premium of $\$ 2.98$ per pound. However, organic products represent only 4 percent of the steak market. Consequently, determining whether to target a steak product to this market requires understanding not only the added cost of doing so but also the elasticity of demand for the product. Similarly, a particular steak brand may enjoy a premium price in the market that is associated with both demand and supply for that brand. In designing strategies for expanding or contracting a brand's presence, elasticity of demand for the specific branded 
product must be known. Determining demand elasticities for specific steak product attributes is a logical step for future research.

\section{References}

Abidoye, B.O., H. Bulut, J.D. Lawrence, B. Mennecke, and A.M. Townsend. 2011. "U.S. Consumers' Valuation of Quality Attributes in Beef Products." Journal of Agricultural and Applied Economics 43(1): 1-12.

Achen, C.H. 2005. "Two-Step Hierarchical Estimation: Beyond Regression Analysis." Political Analysis 13(4): 447-456.

Alfnes, F., and K. Rickertsen. 2003. "European Consumers' Willingness to Pay for U.S. Beef in Experimental Auction Markets." American Journal of Agricultural Economics 85(2): 396-405.

Baltagi, B.H. 2008. Econometric Analysis of Panel Data (4th edition). Chichester, West Sussex UK: John Wiley and Sons, Inc.

Banbury, C.M., and W. Mitchell. 1995. "The Effect of Introducing Important Incremental Innovations on Market Share and Business Survival." Strategic Management Journal 16(Special Issue: Technological Transformation and the New Competitive Landscape): 161-182.

Belsley, D.A., E. Kuh, and R.E. Welsch. 1980. Regression Diagnostics. Toronto: John Wiley and Sons, Inc.

Boland, M., and T.C. Schroeder. 2002. "Marginal Value of Quality Attributes for Natural and Organic Beef." Journal of Agricultural and Applied Economics 34(1): 39-49.

Bowman, K.R., and D.E. Ethridge. 1992. "Characteristic Supplies and Demands in a Hedonic Framework: U.S. Market for Cotton Fiber Attributes." American Journal of Agricultural Economics 74(4): 991-1002.

Brester, G.W., P. Lhermite, B.K. Goodwin, and M.C. Hunt. 1993. "Quantifying the Effects of New Product Development: The Case of Low-Fat Ground Beef." Journal of Agricultural and Resource Economics 18(2): 239-250.

Cameron, A.C., and P.K. Trivedi. 2005. Microeconomics: Methods and Applications. New York, NY: Cambridge University Press.

Chiou, G.T., D.T. Chen, and O. Capps, Jr. 1993. "A Structural Investigation of Biotechnological Impacts on Cotton Quality and Returns." American Journal of Agricultural Economics 75(2): 467-478.

Cox, L.J., B.S. McMullen, and P.V. Garrod. 1990. “An Analysis of the Use of Grades and Household Labels in the Retail Beef Market." Western Journal of Agricultural Economics 15(2): 245-253.

Darby, K., M.T. Batte, S. Ernst, and B. Roe. 2006. "Willingness to Pay for Locally Produced Foods: A Customer Intercept Study of Direct Market and Grocery Store Shoppers." Selected paper presented at the 2006 annual meetings of the Agricultural and Applied Economics Association, Long Beach, CA.

Feldkamp, T.J., T.C. Schroeder, and J.L. Lusk. 2005. "Determining Consumer Valuation of Differentiated Beef Steak Quality Attributes." Journal of Muscle Foods 16(1): 1-15.
Feuz, D.M., W.J. Umberger, C.R. Calkins, and B. Sitz. 2004. 'U.S. Consumers' Willingness to Pay for Flavor and Tenderness in Steaks as Determined with an Experimental Auction." Journal of Agricultural and Resource Economics 29(3): 501-516.

FreshLook Marketing Group. 2011. Unpublished data on beef brands in the United States. Hoffman Estates, IL.

Froehlich, E.J., J.G. Carlberg, and C.E. Ward. 2009. "Willingnessto-pay for Fresh Brand Name Beef." Canadian Journal of Agricultural Economics 57: 119-137.

Greene, W.H. 2003. Econometric Analysis (5th edition). Upper Saddle River, NJ: Prentice-Hall, Inc.

Hahn, W.F., and K.H. Mathews, Jr. 2007. "Characteristics and Hedonic Pricing of Differentiated Beef Demands." Agricultural Economics 36(3): 377-393.

Hanagriff, R.D., R.D. Rhoades, and D. Wilmeth. 2009. "Consumer Preferences in Purchasing Beef and the Values They Attribute to Branded Beef Products." Selected paper presented at the 2009 annual meetings of the Southern Agricultural Economics Association, Atlanta, Georgia.

Harrison, G.W., R.M. Harstad, and E.E. Rutstrom. 2004. "Experimental Methods and Elicitation of Values." Experimental Economics 7(2): 123-140.

$\mathrm{Hu}, \mathrm{Y} .2007$. "Effects of Sensory Attributes on Consumer Preferences." Ph.D. dissertation, School of Economics, Washington State University.

Jekanowski, M.D., D.R. Williams II, and W.A. Schiek. 2000. "Consumers' Willingness to Purchase Locally Produced Agricultural Products: An Analysis of an Indiana Survey." Agricultural and Resource Economics Review 29(1): 43-53.

Jusko, K.L., and W.P. Shively. 2005. "Applying a Two-step Strategy to the Analysis of Cross-national Public Opinion Data." Political Analysis 13(4): 327-344.

Kanter, R.M., and D. Brinkerhoff. 1981. "Organizational Performance: Recent Developments in Measurement." Annual Review of Sociology 7: 321-349.

Li, J. 1995. "Foreign Entry and Survival: Effects of Strategic Choices on Performance in International Markets." Strategic Management Journal 16(5): 333-351.

Loureiro, M.L., and J.J. McCluskey. 2000. "Assessing Consumer Response to Protected Geographical Identification Labeling." Agribusiness 16(3): 309-320.

Loureiro, M.L., and W.J. Umberger. 2003. "Estimating Willingness to Pay for Country-of-Origin Labeling." Journal of Agricultural and Resource Economics 28(2): 287-301.

Loureiro, M.L., and W.J. Umberger. 2007. "A Choice Experiment Model for Beef: What U.S. Consumer Responses Tell Us about Relative Preferences for Food Safety, Country-of-Origin Labeling, and Traceability." Food Policy 32(4): 496-514.

Lusk, J.L., and J.A. Fox. 2002. "Consumer Demand for Mandatory Labeling of Beef from Cattle Administered Growth Hormones or Fed Genetically Modified Corn." Journal of Agricultural and Applied Economics 34(1): $27-38$.

Lusk, J.L., J.A. Fox, T.C. Schroeder, J. Mintert, and M. Koohmaraie. 2001. "In-store Valuation of Steak Tenderness." American Journal of Agricultural Economics 83(3): 539-550. 
Lusk, J.L., J. Roosen, and J.A. Fox. 2003. "Demand for Beef from Cattle Administered Growth Hormones or Fed Genetically Modified Corn: A Comparison of Consumers in France, Germany, the United Kingdom, and the United States." American Journal of Agricultural Economics 85(1): 16-29.

Martinez, S.W. 2008. "Estimating the Value of Retail Beef Product Brands and Other Attributes." Selected paper presented at the 2008 annual meetings of the Agricultural and Applied Economics Association, Orlando, Florida.

McGarry-Wolf, M., and A.J. Thulin. 2000. “A Target Consumer Profile and Positioning for Promotion of a New Locally Branded Beef Product." Journal of Food Distribution Research 31(1): 193-197.

Menkhaus, D.J., G.W. Borden, G.D. Whipple, E. Hoffman, and R.A. Field. 1992. "An Empirical Application of Laboratory Experimental Auctions in Marketing Research." Journal of Agricultural and Resource Economics 17(1): 44-55.

National Cattlemen's Beef Association. 2010. "2010 National Meat Case Study." Centennial, CO: Cattlemen's Beef Board and National Cattlemen's Beef Association.

Outlaw, J.L., D.P. Anderson, and D.I. Padberg. 1997. "Relationships between Market Price Signals and Production Management: The Case of Fed Beef." Journal of Agricultural and Applied Economics 29(1): 37-44.

Owen, K., V. Wright, and G. Griffith. 2000. "Quality, Uncertainty, and Consumer Valuation of Fruits and Vegetables." Australian Agribusiness Review 8: Paper 4. Available at http://www.agrifood.info/review/2000/Owen.html.

Parcell, J.L., and T.C. Schroeder. 2007. "Hedonic Retail Beef and Pork Prices." Journal of Agricultural and Applied Economics 39(1): 29-46.

Platter, W.J., J.D. Tatum, K.E. Belk, S.R. Koontz, P.L. Chapman, and G.C. Smith. 2005. "Effects of Marbling and Shear Force on Consumers' Willingness to Pay for Beef Strip Loin Steaks." Journal of Animal Science 83(4): 890-899.

Rosen, S. 1974. "Hedonic Prices and Implicit Markets: Product Differentiation in Pure Competition." The Journal of Political Economy 82(1): 34-55.

Shongwe, M.A., A. Jooste, A. Hugo, Z.G. Alemu, and A. Pelser. 2007. "Will Consumers Pay for Less Fat on Beef Cuts? The Case in Bloemfontein, South Africa." Agrekon 46(4): 475-493.
Suarez, F.F., and J.M. Utterback. 1995. "Dominant Designs and the Survival of Firms." Strategic Management Journal 16(6): 415-430.

Thilmany, D., J. Grannis, and E. Sparling. 2003. "Regional Demand for Natural Beef Products in Colorado: Target Consumers and Willingness to Pay." Journal of Agribusiness 21(2): 149-165.

TheBeefCheck-off.2008.BeefTrainingCamp:Steak. Centennial, CO: Cattlemen's Beef Board and National Cattlemen's Beef Association. Available at http://www.beefretail.org/ CMDocs/BeefRetail/btc/BTCSteak.pdf.

Tonsor, G.T., T.C. Schroeder, J.A. Fox, and A. Biere. 2005. "European Preferences for Beef Steak Attributes." Journal of Agricultural and Resource Economics 30(2): 367-380.

Tonsor, G.T., T.C. Schroeder, and J.M.E. Pennings. 2009. "Factors Impacting Food Safety Risk Perceptions." Journal of Agricultural Economics 60(3): 625-644.

Umberger, W.J., D.M. Feuz, C.R. Calkins, and B.M. Sitz. 2003. "Country-of-Origin Labeling of Beef Products: U.S. Consumers' Perceptions." Journal of Food Distribution Research 34(3): 103-116.

Unnevehr, L.J., and S. Bard. 1993. "Beef Quality: Will Consumers Pay for Less Fat?" Journal of Agricultural and Resource Economics 18(2): 288-295.

U.S. Department of Agriculture. 2010 National Organic Program. USDA, Washington, D.C. Available at http:// www.ams.usda.gov/AMSv1.0/nop.

Ward, C.E., J.L. Lusk, and J.M. Dutton. 2008. "Implicit Value of Retail Beef Product Attributes." Journal of Agricultural and Resource Economics 33(3): 364-381.

Wooldridge, J.M. 2002. Econometric Analysis of Cross Section and Panel Data. Cambridge: MIT Press.

Wu, D.M. 1973. "Alternative Tests of Independence between Stochastic Regressors and Disturbances." Econometrica 41(4): 733-750.

Yanik, F.F., E. Malatyalioglu, I. Kocak, I. Bolat, A. Kokcu, M.I. Fernandez, and B.W. Woodward. 1999. "Comparison of Conventional and Organic Beef Production Systems, I: Feedlot Performance and Production Costs." Livestock Production Science 61(2): 213-223.

Zeithaml, V.A. 1988. "Consumer Perceptions of Price, Quality, and Value: A Means-End Model and Synthesis of Evidence." The Journal of Marketing 52(3): 2-22. 
lowa State University does not discriminate on the basis of race, color, age, religion, national origin, sexual orientation, gender identity, genetic information, sex, marital status, disability, or status as a U.S. veteran. Inquiries can be directed to the Director of Equal Opportunity and Compliance, 3280 Beardshear Hall, (515) 294-7612. 